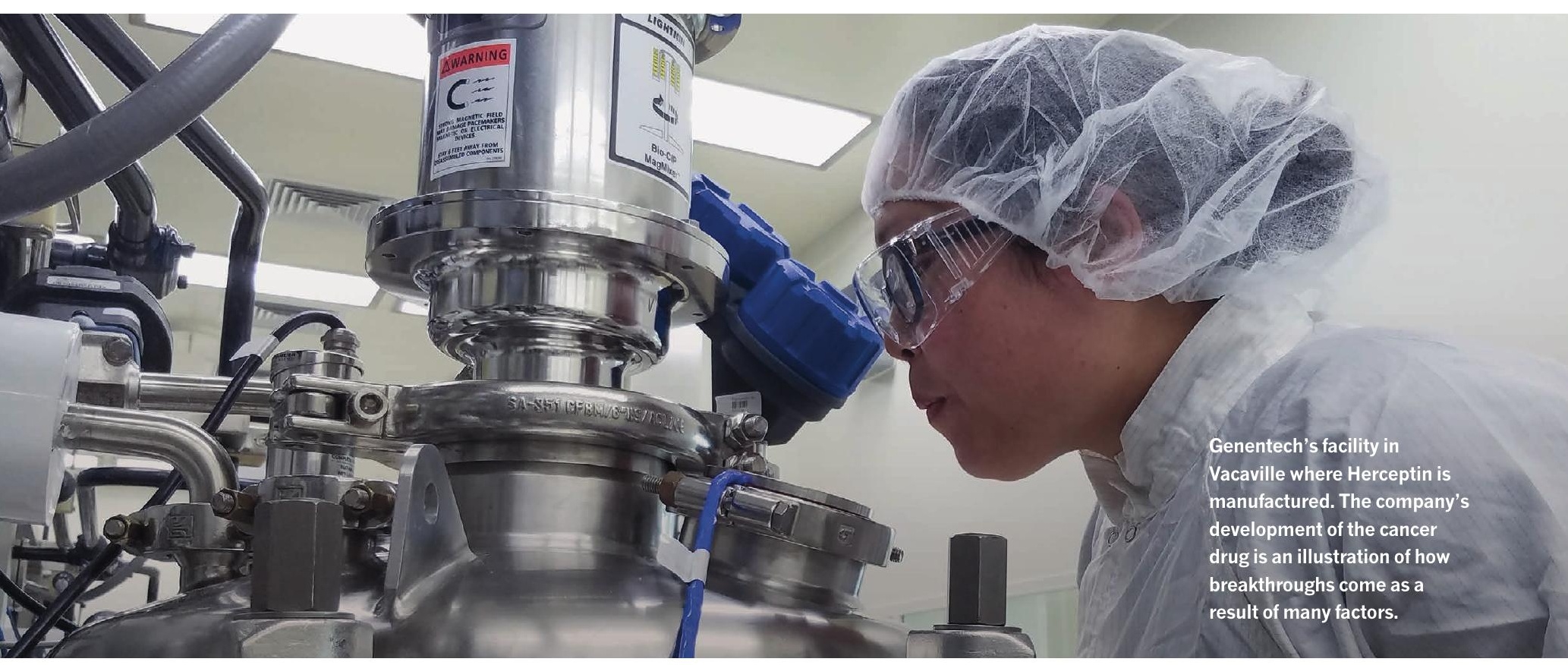

\title{
CONNECTING BIG IDEAS TO BENEFIT
}

$\mathrm{F}$ ollowing the transfer of scientific knowledge into industry and the economy is a growing priority for governments and research funding agencies. In this Nature Index supplement we explore the connection between high-quality research and the development and commercialization of new products and services.

$A$ variety of metrics and measurements are used to follow the path of an idea as it becomes an invention - from papers and patents, to case studies and corporate revenue. In this supplement, we consider data from the index, an indicator of high-quality science, with data from the Lens platform, an open patent database that links scholarly articles to the patents in which they have been cited (see Tables, page S33). When a patent document cites a research paper, we can infer that the scholarly work may have influenced or enabled the invention. In this way these citations can be viewed as a proxy for industry's reliance on scientific knowledge.

A perfect illustration of this correlation is the work of biochemist Michael Sporn, page S16. More than half of his papers published between 1959 and 2006 have been cited in patents, which have in turn led to numerous drugs in clinical development for cancer, fibrosis and other diseases. One paper by bioinformatician, David
Lipman, and his team reported on a database that allowed researchers to search for or compare DNA sequences. The paper has been cited by more than 4,900 patent families, according to the Lens database, which links more than 100 million publicly available patent documents to more than a million scholarly articles. On page S8, Lens founder Richard Jefferson argues that linking these corpora in a free, open, private and secure format encourages scientists and investors to discover and build bridges with other actors in the innovation system.

For another perspective on the link between research and innovation, the tables also rank a selection of high-performing institutions in the index, based on their patent numbers relative to their published research output.

New tools to understand science-technology links beyond papers and patents are also in development. An example is a programme in the United States that traces highly-skilled researchers as they move through the job market (see page S23). This undertaking is revealing a more complete picture of the interdependence between research, industry and the economy.

\section{Nicky Phillips}

Editor, Nature Index
EDITORIAL: Nicky Phillips, Stephen Pincock, Rebecca Dargie, Herb Brody, Victoria Kitchener, Sujata Gupta, Neil Savage, Elie Dolgin, Branwen Morgan, Annabel McGilvray. ANALYSIS: Aaron Ballagh. ART \& DESIGN: Alisdair Macdonald, Kate Duncan, Mohamed Ashour, Wojtek Urbanek, Chris Gilloch, Ruffi Lu, Chika Takeda. WEB \& DESIGN: Bob Edenbach, Olivier Lechevalier Naomi Nakahara, Pamela Sia, Bart Riepe. DATA QUALITY: Jörn Ishikawa, Yuxin Wang, Jennie Pao, Paul Glaeser. PRODUCTION: Sue Gray, Karl Smart, Ian Pope, Matt Carey, Ali Mosud, Nik Spencer. MARKETING: Alan Abery. PROJECT MANAGEMENT: Rebecca Jones. SALES: Janet Cen, Yuki Fujiwara, Maki Ishikawa, Rory Mulkerrins, Stella Yan, Tommy Yim, Joan Yin. ART DIRECTOR: Kelly Buckheit Krause. PUBLISHING: Nick Campbell, Richard Hughes, David Swinbanks.

NATURE INDEX 2017 INNOVATION Nature Index 2017 Innovation, a supplement to Nature, is produced by Nature Research, the flagship science portfolio of Springer Nature. This publication is based on data from the Nature Index, a Nature Research website maintained and made freely available at natureindex.com

NATURE EDITORIAL OFFICES The Campus, 4 Crinan Street, London N1 9XW, UK Tel: $+44(0) 2078334000$ Fax: +44(0)20 7843 4596/7

\section{CUSTOMER SERVICES} To advertise with the Nature Index, please visit natureindex.com/client-services feedback@nature.com Copyright @ 2017 Macmillan Publishers Limited, part of Springer Nature. All rights reserved. 